REVISTA INTERNACIONAL DE CIENCIAS DEL DEPORTE International Journal of Sport Science

Rev. int. cienc. deporte

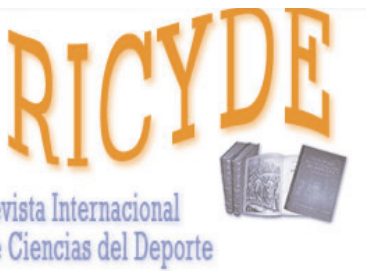

International Journal of Sport Science VOLUMEN X - AÑO X

Páginas:123-130 ISSN:1885-3137 No 36 - Abril - 2014

\title{
Comparison Of Two Systems Designed To Measure Vertical Jump Height Comparación de dos sistemas diseñados para medir altura de salto vertical
}

\author{
Alejandro Santos-Lozano \\ University of León \\ Rafael Gascón \\ IES ÍTACA. Zaragoza, Huesca \\ Isaac López \\ C.B. CAI Zaragoza, Huesca \\ Nuria Garatachea-Vallejo \\ University of Zaragoza, Huesca
}

\begin{abstract}
The vertical jump height is commonly employed to assess indirectly the lower body strength and power. Traditional methods to assess the vertical jump height are been replaced by new emerging technologies as optical mat platform. The aim of the present study was checked the agreement between one traditional contact mat (Globus Ergo Tester) and an optical mat (Optojump System), and to investigate the interchangeability of this 2 commercial systems estimating vertical jump in different types of jump (Squat Jump, Counter Movement Jump and Abalakov). Significantly differences between methods in each jump condition were reported, high Inter-class Correlation Coefficients values (ranged between 0.972 to 0.990 ) were found between methods in each jump condition and the coefficient of variation values were ranged from 6.18 to 7.32. T-test revealed significantly differences between the limits of agreement at 95\% in all jumps between methods jump heights. The results of this study show that the Optojump, as optical mat, reported lower values than the Globus Ergo Tester, a contact mat. There are evidences that Optojump and Globus Ergo Tester are not interchangeably.
\end{abstract}

Key words: flight time; vertical jump; contact mat platform; optical mat platform.

\section{Resumen}

La altura de salto vertical es empleada para evaluar la potencia y fuerza del tren inferior. Los métodos tradicionales para evaluar el salto vertical están siendo sustituidos por nuevas tecnologías emergentes como las plataformas ópticas. El objetivo del presente estudio fue comprobar el grado de concordancia entre una plataforma de contacto (Globus Ergo Tester) y una óptica (Optojump System), e investigar si pueden ser utilizadas de manera intercambiable estimando distintos tipos de salto vertical (Squat Jump, Counter Movement Jump y Abalakov). Los resultados mostraron diferencias significativas entre los métodos estimando altura de salto vertical, un elevado valor de Coeficiente de Correlación (entre 0.972-0.990) y un Coeficiente de Variación comprendido entre 6.18 y 7.32. Las pruebas $T$ revelaron diferencias significativas entre los límites de concordancia al $95 \%$ en todos los saltos entre plataformas. Los resultados del presente estudio muestran como el sistema óptico, Optojump, estimó valores más bajos que la plataforma por contacto, Globus Ergo Tester. Existen evidencias por tanto que estos sistemas no pueden ser utilizados intercambiablemente.

Palabras clave: tiempo de vuelo, salto vertical, plataformas de contacto, plataformas ópticas. 
Santos-Lozano, A.; Gascón, R.; López, I., \& Garatachea-Vallejo, N. (2014). Comparison Of Two Systems Designed To Measure Vertical Jump Height. RICYDE. Revista internacional de ciencias del deporte, 36(10), 123-130 http://dx.doi.org/10.5232/ricyde2014.03603

\section{Introduction}

Since Bosco, Luhtanen and Komi (1983) defined a battery test to assess indirectly the lower body strength and power, the vertical jump height is commonly used in sport scientists to evaluate athletic (Chaabene, Hachana, Franchini, Mkaouer, \& Chamari, 2012; Higham, Pyne, Anson, \& Eddy, 2012; Ostojic, Mazic, \& Dikic, 2006; Schaal, Ransdell, Simonson, \& Gao, 2012) and non-athletic population such as older people (Bosco \& Komi, 1980; Muehlbauer, Besemer, Wehrle, Gollhofer, \& Granacher, 2012), obese people (Dumith, Ramires, Souza, Moraes, Petry, Oliveira, Ramires, \& Hallal, 2010; Rauch, Veilleux, Bock, Welisch, Filler, Robinson, \& Norozi, 2012; RiddifordHarland, Steele, \& Baur, 2006) or children (Eather, Morgan, \& Lubans, 2012; Souissi, Chtourou, Chaouachi, Dogui, Chamari, Souissi, \& Amri, 2012).

Several methods can be used to determine the vertical jump height: traditional methods like distant between marks, motion analysis pc-system, force platform and contact platform. The most extended method is the contact platform because this device is inexpensive, in comparison with force platform, need fewer training to operate than motion analysis pc-system, and the results are immediate and provide a good reliability between measures (Nuzzo, Anning, \& Scharfenberg, 2011). The mechanism of the contact platform consists in a mat that have inside metallic bars. The jump height is determined by the flight-time, which is measured by the time in which the system detects any breaks in contact between the metallic bars (Young, MacDonald, \& Flowers, 2001). Some of these classical contact platforms are the Just Jump System, the Vertec or the Globus Ergo Tester. However, a recently modern contact platform was developed replacing the mat by an optical measurement system consisting of a transmitting and receiving bar, which contains leds. The system detects any interruptions in communication between the bars and calculates their duration (flighttime), this mats provide many advantages over traditional because they are generally more efficient and can therefore accommodate larger subjects in shorter periods of time. The IDEA System, ErgoJump Plus, the SportJump System Pro, the IR-Mat or the Optojump are examples of this currently technology (Bosquet, Berryman, \& Dupuy, 2009; Garcia-Lopez, Morante, Ogueta-Alday, \& Rodriguez-Marroyo, 2012; Kenny, A, \& Comyns, 2012).

Consequently two different kinds of contact platform co-exist in the market at the moment: the traditional comprised by a mat and the newest composed by an optical system. So, it is needed know the agreement between technologies. For this reason we choose two different methods estimating height jump, the Globus Ergo Tester and Optojump System, to develop the present study and to check the agreement between them, and to investigate the interchangeability of this 2 commercial systems.

\section{Material and methods}

28 volunteered participants (aged between 18-28 years) were evaluated using simultaneously the Globus Ergo Tester and the Optojump system (figure 1). Each participants, after a warm-up of $5 \mathrm{~min}$ walking at $6 \mathrm{~km} \cdot \mathrm{h}^{-1}$ and 5 min running at $8 \mathrm{~km} \cdot \mathrm{h}^{-}$ ${ }^{1}$, performed twice the next vertical jump battery test: a maximal Squat Jump (SJ) with a $90^{\circ}$ knee flexion defined, a maximal SJ with a free knee flexion, a Counter Movement Jump (CMJ) with a flexion defined in $90^{\circ}$, a CMJ with a free flexion and an Abalakov Jump. Previously, participants developed a two-familiarization sessions. 


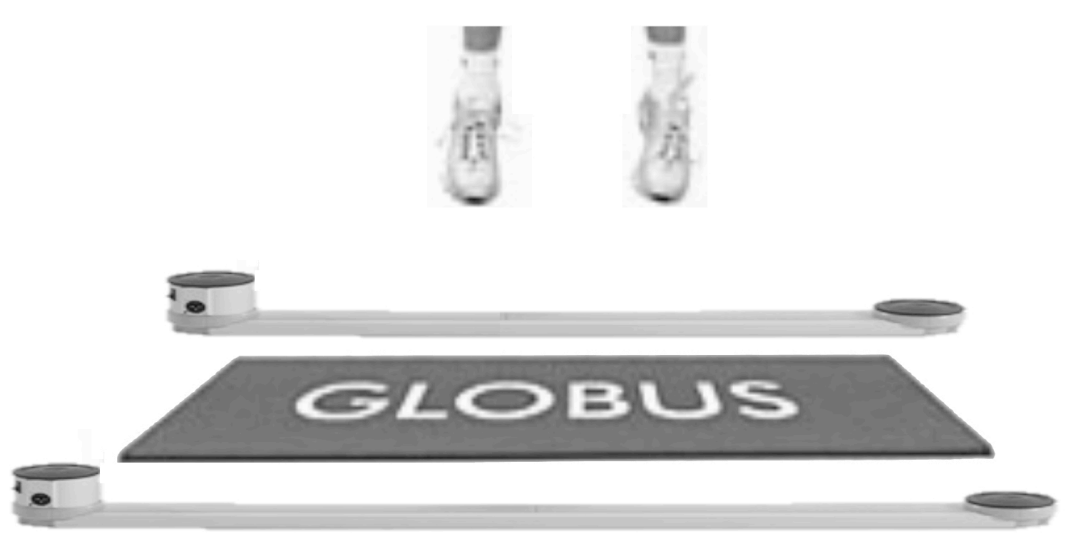

Figure 1. Positioning of the devices during the measurement

The University Review Board approved the research project and it was in agreement with the Declaration of Helsinkifor Human Research of 1974 (last modified in 2000).

\section{Measurements}

Globus Ergo Tester (Codognè, Italy) is an electronic contact mat system with a sample rate of $1000 \mathrm{~Hz}$. The mat have inside metallic bars and the jump height is determined using an acknowledged flight-time calculation that is measure by the time in which the system detects any breaks in contact between the metallic bars.

Optojump (Microgate S.R.L., Bonzano, Italy) is an optical measurement system consisting of a transmitting and receiving bar, which contains form 33 to 100 leds. The leds on the transmitting bar communicate continuously and the system detects any interruptions in communication between the bars and calculates their duration. It is possible to measure flight and contact times during the performance with an accuracy of $1 \cdot 1000^{-1}$ of a second.

\section{Statistical Analysis}

All statistical analyses were performed with PASW (Predictive Analytics Software for MAC, v. 20.0 SPSS Inc., Chicago, IL, USA). Descriptive data are presented as means \pm standard deviation (SD) and significance level was set at $P \leq 0.01$.

To study differences between methods across the aforementioned jump conditions on jump height, a one-way ANOVA was used for each jump condition. To examine the inter-class variability within methods for each jump condition (SJ $90^{\circ}$, SJ Free, CMJ $90^{\circ}, \mathrm{CMJ}$ Free and AB), we calculated the intra-class correlation coefficients (ICC) and coefficient of variation (CV). Also, a two-way ANOVA factor [Test (1 or 2) x method (Globus Ergo Tester or Optojump system) were used to determine the test and methods effect. When the assumptions of sphericity were violated, we applied the Greenhouse Geisser correction factor. A Bonferroni post hoc test was used in all pairwise comparisons when a significant result was found.

Moreover, to study agreement between methods, systematic error (bias or mean intermonitor differences) and random error (95\% limits of agreement, mean difference \pm SD of the difference multiplied by 1.96) between methods was determined using Bland \& Altman plots. The paired $t$-test was used to analyse significant differences in bias between methods measure. In addition, the association between the difference and the 
magnitude of the measurement (i.e. heteroscedasticity) was examined by regression analysis (Atkinson, Davison, \& Nevill, 2005; Atkinson \& Nevill, 1998). For the latter analysis, the difference between Globus Ergo Tester jump height and Optojump system jump height was entered as the dependent variable, whereas the averaged value [(Globus Ergo Tester jump height + Optojump system jump height)/2] was entered as the independent variable in each jump condition.

\section{Results}

Figure 2 shows the mean jump height for each jump condition measured by each method (Globus Ergo Tester or Optojump system). The one-way ANOVA factor found significantly differences between methods in each jump condition. The two-way ANOVA showed a significant interaction effect in test 1 or 2 and the method used; Bonferroni post hoc revealed differences between the Globus Ergo Tester and Optojump system in both test.

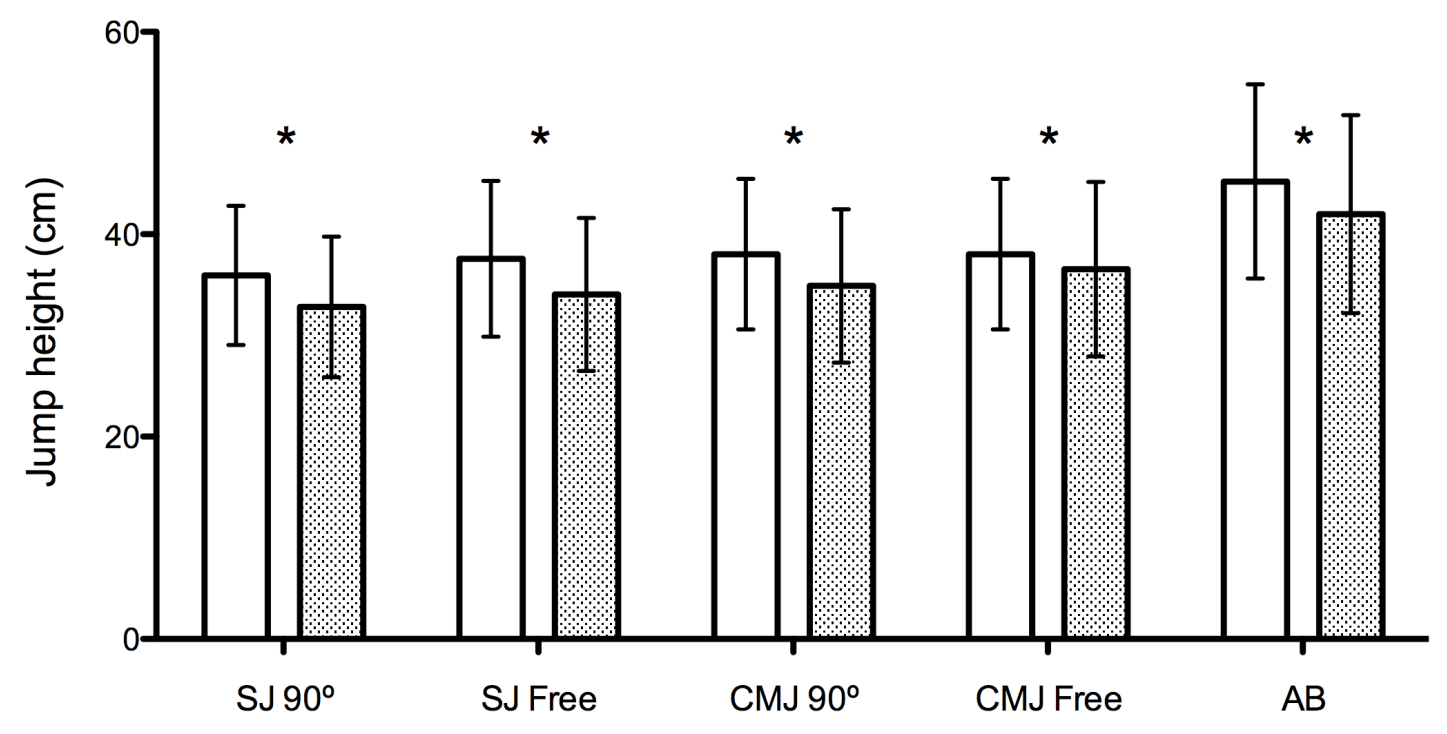

Jump condition

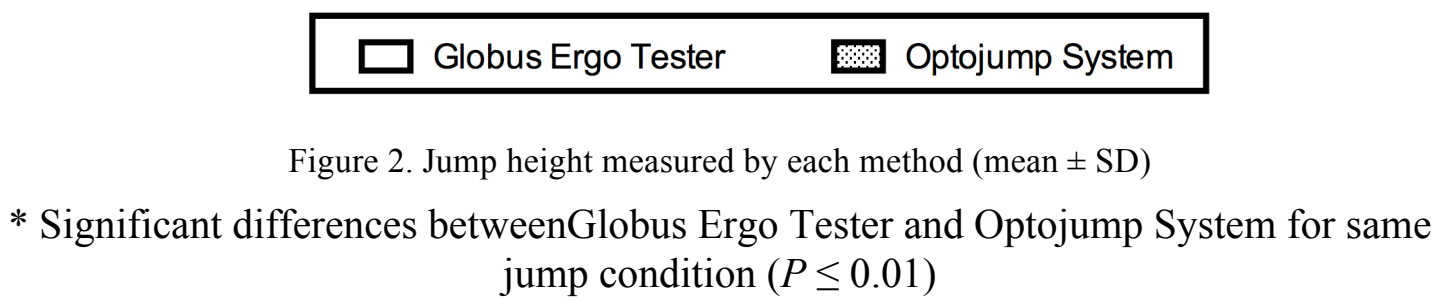

High Inter-class Correlation Coefficients (ICC ranged between 0.972 to 0.990 ) values were found between methods in each jump condition (table 1) and coefficient of variation $(\mathrm{CV})$ values were ranged from 6.18 to 7.32 (table 1). 
Santos-Lozano, A.; Gascón, R.; López, I., \& Garatachea-Vallejo, N. (2014). Comparison Of Two Systems Designed To Measure Vertical Jump Height. RICYDE. Revista internacional de ciencias del deporte, 36(10), 123-130 http://dx.doi.org/10.5232/ricyde2014.03603

Table 1. ICC and CV for each jump condition.

\begin{tabular}{|l|c|c|}
\hline \multicolumn{1}{|c|}{ Jump condition } & ICC & CV \\
\hline Squat jump 90 & 0.981 & $6.76( \pm 4.59)$ \\
\hline Squat jump free & 0.972 & $7.32( \pm 6.06)$ \\
\hline Counter movement jump 90 & 0.985 & $6.45( \pm 5.10)$ \\
\hline Counter movement jump free & 0.990 & $6.85( \pm 4.46)$ \\
\hline Abalakov & 0.990 & $6.18( \pm 3.49)$ \\
\hline
\end{tabular}

ICC: Inter-class coefficient of correlation

$\mathrm{CV}$ : Coefficient of variation

Bland \& Altman plots for Globus Ergo Tester are shown in figure 3. T-test revealed significantly differences between the limits of agreement at $95 \%$ in all jumps between Globus Ergo Tester jump height and Optojump system jump height. Moreover, the heteroscedasticity analysis showed "homeocedasticity", no significantly correlation between the dependent variable (difference between Globus Ergo Tester jump height and Optojump system jump height) and the independent variable [(Globus Ergo Tester jump height + Optojump system jump height $) / 2$ ] to $\mathrm{SJ} 90^{\circ}(\mathrm{R}=-0.037 ; P=0.789)$, SJ free $(\mathrm{R}=0.043 ; P=0.750), \mathrm{CMJ} 90(\mathrm{R}=-0.068 ; P=0.619)$, CMJ free $(\mathrm{R}=-0.12 ; P=0.930)$ and $\mathrm{AB}(\mathrm{R}=-0.82 ; P=0.547)$.
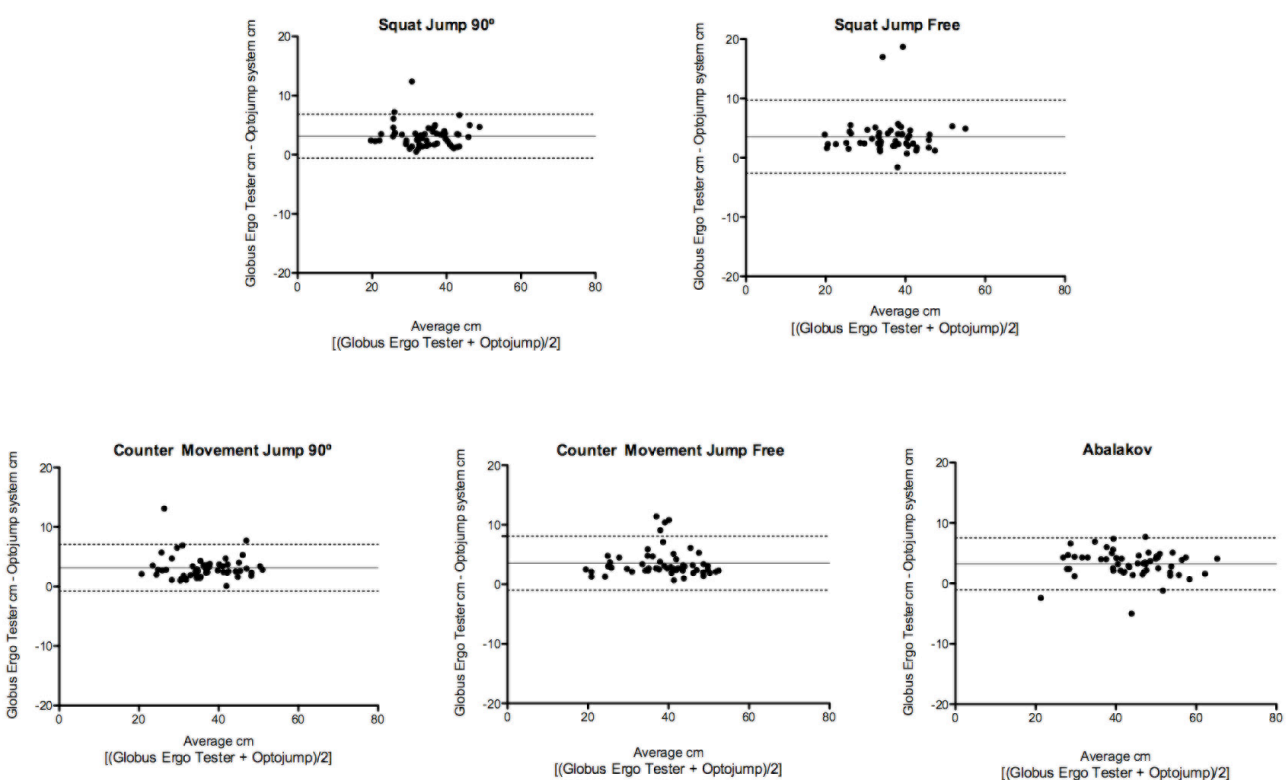

Figure 3. Bland and Altman plots per each jump condition 
Santos-Lozano, A.; Gascón, R.; López, I., \& Garatachea-Vallejo, N. (2014). Comparison Of Two Systems Designed To Measure Vertical Jump Height. RICYDE. Revista internacional de ciencias del deporte, 36(10), 123-130 http://dx.doi.org/10.5232/ricyde2014.03603

\section{Discussion}

The purpose of the present work was to compare the vertical height jump estimated by two different commercial contact mats: an optical system (Optojump) and traditional contact mat (Globus Ergo Tester). In our knowledge this is the first study that compared this devices. Vertical jump showed differences $(P \leq 0.01)$ when measured by Optojump system or Globus Ergo Tester for all jumps conditions (SJ, CMJ with $90^{\text {a }}$ knee and free flexion, as well as the Abalakov). Flight time was systematically higher when was measured by the Globus Ergo Tester in all jumps conditions; this is in agreement with others previous works in which flight time or height vertical jump were lower in comparison with an optical system is used (Garcia-Lopez et al., 2012; Glatthorn, Gouge, Nussbaumer, Stauffacher, Impellizzeri, \& Maffiuletti, 2011). Glatthorn et al. (2011) checked the validity and reliability the Optojump system founding great testretest reliability (ICCs from 0.982 to 0.989 between trials, CVs of range from 2.2 to $3.1 \%$ and random errors of 62.81). However, the Optojump system presented a consistently error of $-1.06 \mathrm{~cm}(P<0.001)$ compared with the gold standard (force place) that could be corrected by the next equation (force plate jump height $(\mathrm{cm})=1.02$. Optojump jump height +0.29 ) to use the force plate or the Optojump interchangeably, although it is important to note that this equation has not been cross validated until now. Heteroscedasticity analysis showed that the variability was similar independently the magnitude of the measurements.

Optojump reliability: the test-retest CVs of SJ and CMJ height obtained in the present study using the Optojump system (range: 2.2-3.1\%) are in the lower range of those reported in the meta-analytic review by Hopkins et al. (9) (range: 3.1-8.6\%), where jump height and power were measured using yardsticks, contact mats, and force plates

Although the ICC showed high values and the Bland and Altman analysis revealed an acceptable BIAS in a clinical perspective, the CV values were higher than $10 \%$ in many records (table 1), which is the common criteria used in the past as regarding reliability analysis (Atkinson \& Nevill, 1998). CVs values indicate that it affected the consistency of measurements between devices. Recently García-López et al. (2012) checked the influence of the type of mat (contact or photocell) estimating flight time. They checked two models of photocell mats (the ErgoJump Plus and the SportJump System Pro) and one contact mat (the SportJump-v 1.0) concluding that the type of mat affected $\sim 6 \%$ the vertical jump height. They also used a gold standard method to compare the results (a Force Plate) and after the analysis they revealed that the photocells mat underestimate the height jump, and both photocells showed a high correlation and a good reliability ( $\mathrm{r}=0.999$ and $0.676, \mathrm{CV}=2.98 \%$ and $15.94 \%, \mathrm{ICCs}=0.95-0.97$ and $0.45-0.57$, respectively). Previously, Bosquet et al. (2009) compared the Optojump with the IRmat, another optical mats, concluding that both devices could be used interchangeability (the means of BIAS were $1 \%$ of the mean performance for flight time and $\sim 2 \%$ for jumping height), in spite of they found that the flight time measured with the IR-mat was higher that the measured with the Optojump $(P<0.001)$. 
Santos-Lozano, A.; Gascón, R.; López, I., \& Garatachea-Vallejo, N. (2014). Comparison Of Two Systems Designed To Measure Vertical Jump Height. RICYDE. Revista internacional de ciencias del deporte, 36(10), 123-130 http://dx.doi.org/10.5232/ricyde2014.03603

\section{Conclusions}

Therefore the results of this study agree with the scientific literature showing that the Optojump, as optical mat, reported lower values than the Globus Ergo Tester, a contact mat. Further research is needed to determine if exists differences between the new optical mats models and traditional contact mat models to allow to professionals used interchangeability models to assess the vertical height jumps and time of flight. So, according to the present work, there are evidences that Optojump and Globus Ergo Tester do not provide similar vertical jump height.

\section{References}

Atkinson, G.; Davison, R. C., \& Nevill, A. M. (2005). Performance characteristics of gas analysis systems: what we know and what we need to know. International Journal of Sports Medicine, 26 Suppl 1, S2-10. http://dx.doi.org/10.1055/s-2004-830505

Atkinson, G., \& Nevill, A. M. (1998). Statistical methods for assessing measurement error (reliability) in variables relevant to sports medicine. Sports Medicine, 26(4), 217-238.

http://dx.doi.org/10.2165/00007256-199826040-00002

Bosco, C., \& Komi, P. V. (1980). Influence of aging on the mechanical behavior of leg extensor muscles. European Journal of Applied Physiology, 45(2-3), 209219. http://dx.doi.org/10.1007/BF00421329

Bosco, C.; Luhtanen, P., \& Komi, P. V. (1983). A simple method for measurement of mechanical power in jumping. European Journal of Applied Physiology, 50(2), 273-282.

http://dx.doi.org/10.1007/BF00422166

Bosquet, L.; Berryman, N., \& Dupuy, O. (2009). A comparison of 2 optical timing systems designed to measure flight time and contact time during jumping and hopping. Journal Of Strength And Conditioning Research, 23(9), 2660-2665. http://dx.doi.org/10.1519/JSC.0b013e3181b1f4ff

Chaabene, H.; Hachana, Y.; Franchini, E.; Mkaouer, B., \& Chamari, K. (2012). Physical and physiological profile of elite karate athletes. Sports Medicine, 42(10), 829-843.

Dumith, S. C., Ramires, V. V., Souza, M. A., Moraes, D. S., Petry, F. G., Oliveira, E. S., Ramires, S. V., \& Hallal, P. C. (2010). Overweight/obesity and physical fitness among children and adolescents. Journal of Physical Activity and Health, $7(5), 641-648$.

Eather, N.; Morgan, P. J., \& Lubans, D. R. (2012). Improving the fitness and physical activity levels of primary school children: Results of the Fit-4-Fun group randomized controlled trial. Preventive Medicine, 56(1), 12-19.

http://dx.doi.org/10.1016/j.ypmed.2012.10.019

Garcia-Lopez, J.; Morante, J. C.; Ogueta-Alday, A., \& Rodriguez-Marroyo, J. A. (2012). The type of mat (contact vs. photocell) affects vertical jump height estimated from flight time. Journal Of Strength And Conditioning Research, 27(4):1162-1167.

http://dx.doi.org/10.1519/JSC.0b013e31826520d7 
Santos-Lozano, A.; Gascón, R.; López, I., \& Garatachea-Vallejo, N. (2014). Comparison Of Two Systems Designed To Measure Vertical Jump Height. RICYDE. Revista internacional de ciencias del deporte, 36(10), 123-130 http://dx.doi.org/10.5232/ricyde2014.03603

Glatthorn, J. F.; Gouge, S.; Nussbaumer, S.; Stauffacher, S.; Impellizzeri, F. M., \& Maffiuletti, N. A. (2011). Validity and reliability of Optojump photoelectric cells for estimating vertical jump height. Journal Of Strength And Conditioning Research, 25(2), 556-560.

http://dx.doi.org/10.1519/JSC.0b013e3181ccb18d

Higham, D. G.; Pyne, D. B.; Anson, J. M., \& Eddy, A. (2012). Physiological, Anthropometric and Performance Characteristics of Rugby Sevens Players. Int $J$ Sports Physiology and Performance, 8(1), 19-27.

Kenny, I. C.; A, O. Caireallain, \& Comyns, T. M. (2012). Validation of an electronic jump mat to assess stretch-shortening cycle function. Journal Of Strength And Conditioning Research, 26(6), 1601-1608.

Muehlbauer, T.; Besemer, C.; Wehrle, A.; Gollhofer, A., \& Granacher, U. (2012). Relationship between Strength, Power and Balance Performance in Seniors. Gerontology, 58(6), 504-512.

http://dx.doi.org/10.1159/000341614

Nuzzo, J. L.; Anning, J. H., \& Scharfenberg, J. M. (2011). The reliability of three devices used for measuring vertical jump height. Journal Of Strength And Conditioning Research, 25(9), 2580-2590.

http://dx.doi.org/10.1519/JSC.0b013e3181fee650

Ostojic, S. M.; Mazic, S., \& Dikic, N. (2006). Profiling in basketball: physical and physiological characteristics of elite players. Journal of Strength And Conditioning Research, 20(4), 740-744.

Rauch, F.; Veilleux, L. N.; Bock, D.; Welisch, E.; Filler, G.; Robinson, T., \& Norozi, K. (2012). Muscle force and power in obese and overweight children. Journal of Musculoskeletal and Neuronal Interactions, 12(2), 80-83.

Riddiford-Harland, D. L.; Steele, J. R., \& Baur, L. A. (2006). Upper and lower limb functionality: are these compromised in obese children? International Journal of Pediatric Obesity, 1(1), 42-49.

http://dx.doi.org/10.1080/17477160600586606

Schaal, M.; Ransdell, L.; Simonson, S., \& Gao, Y. (2013). Physiologic Performance Test Differences in Female Volleyball Athletes by Competition Level and Player Position. Journal Of Strength And Conditioning Research, 27(7), 1841-1850

Souissi, H.; Chtourou, H.; Chaouachi, A.; Dogui, M.; Chamari, K.; Souissi, N., \& Amri, M. (2012). The effect of training at a specific time-of-day on the diurnal variations of short-term exercise performances in 10- to 11-year-old boys. Pediatric Exercise Science, 24(1), 84-99.

Young, W. B.; MacDonald, C., \& Flowers, M. A. (2001). Validity of double- and single-leg vertical jumps as tests of leg extensor muscle function. Journal of Strength And Conditioning Research, 15(1), 6-11. 